\title{
A REVIEW ON OLIVE OIL AND Nigella sativa L. BLACK CUMIN SEED OIL: COMPOSITION AND BIOLOGICAL ACTIVITY
}

\author{
Nesrain Farhan, Nadia Salih $\bowtie$ and Jumat Salimon \\ Department of Chemical Sciences, Faculty of Science and Technology, Universiti Kebangsaan \\ Malaysia, 43600 Bangi, Selangor, Malaysia \\ ${ }^{\square}$ Corresponding Author: nadiaalnami@hotmail.com
}

\begin{abstract}
Olive oil and black cumin seed oil have large areas of applications, and the most important of them are medical applications. They can be used to treat skin diseases. The black cumin seed oil has been used to treat eczema and psoriasis, while olive oil has been used to treat eczema and protect the skin. Many cosmetics products contain olive oil and black cumin seed oil. The major fatty acids composition of olive oil is palmitic acid (7.5-20\%), oleic acid (55$83 \%$ ), and linoleic acid (3.5-21\%). The black cumin seed oil contains moisture, fat, protein, ash and total carbohydrates contents were in the range of 3.8 to $7.0 \%, 22.0$ to $40.4 \%, 20.9$ to $31.2 \%, 3.7$ to $4.7 \%$ and 24.9 to $40 \%$, respectively. Oleic and linoleic acids are essential fatty acids. These essential fatty acids are substances that the body needs in order to maintain cellular health as well as to prevent inflammation in the body. In this review, our motivation is to provide a comprehensive review of olive and Nigella sativa L. black cumin oils - their composition and biological activity. Keywords: Olive Oil, Nigella sativa L., Black Cumin Oil, Physicochemical Properties, Biological Effect
\end{abstract}

RASĀYAN J. Chem., Vol. 14, No.4, 2021

\section{INTRODUCTION}

Olive oil is a major agricultural commodity for the European Union with California. $75 \%$ of olive oil production comes from EU states, $95 \%$ of this amount comes from Spain, Italy and Greece. ${ }^{1,2}$ Olives are considered a new crop in the Kingdom of Saudi Arabia (KSA). During the last fifteen years, national production of olive oil has increased rapidly and there is an enormous potential for olive oil and table olive production in the KSA, especially in the Northern region such as Al-Jouf due to its temperate climate. ${ }^{3-5}$ Extra Virgin olive oil (EVOO) represents one of the most important components of the Mediterranean diet, and it is highly appreciated by consumers thanks to its health benefits and pleasant, particular flavor. EVOO is known to be more resistant to oxidation than other edible oils because of its natural antioxidant content, particularly polyphenols and relatively low content of polyunsaturated fatty acids. EVOO is the highest grade of olive oil and is produced from fresh olives using mechanical extraction processes including crushing of the olive fruits, malaxing of resulting paste and separation of oily phase and without the use of excessive heat chemical interference or blending with other edible oils. ${ }^{6-8}$

Nigella sativa L. (Ranunculaceae), commonly called black cumin seed oil (BCSO) and (Habat Al-barkah) in Saudi Arabia, is an annual herbaceous plant cultivated in different parts of the world, mainly in countries bordering the Mediterranean Sea. ${ }^{9}$ The seeds are used extensively for flavoring and medicinal purposes. $\mathrm{BCSO}$ is used in traditional medicine dating back to the ancient Egyptians, Greeks, and Romans. In recent times, considerable research interest has been devoted worldwide to the investigation of the black seeds for their historically alleged medicinal properties. The black seed oil is popularly used in certain cases of asthma and eczema. Olive and black cumin seed oils are a useful source for nutritional, biological and medical applications. ${ }^{10}$

Olive Products and their Characteristics

The olive tree is a species of small trees in the family Oleaceae, native to the coastal areas of the Eastern Mediterranean Basin as well as northern Iraq, and northern Iran at the south of the Caspian Sea. 
The olive fruit is a small oval bitter fruit with a pit. The olive fruit is a green drupe, becoming generally blackish-purple when fully ripe (Fig.-1). The scientific classification of olive is shown in Table-1.

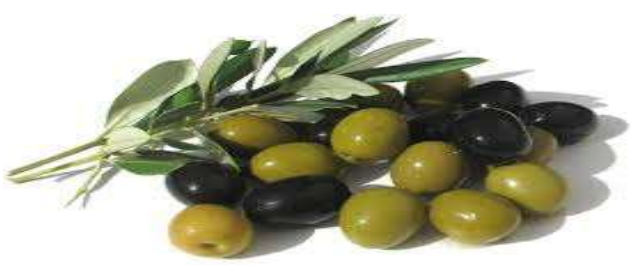

Fig.-1: Olive Fruit

Table-1: The Scientific Classification of Olive

\begin{tabular}{c|c}
\hline Scientific & Classification \\
\hline Kingdom & Plantae \\
\hline Order & Lamiales \\
\hline Family & Oleaceae \\
\hline Genus & Olea \\
\hline Species & O. europaea \\
\hline
\end{tabular}

Over 750 million olive trees are cultivated worldwide, $95 \%$ of which are in the Mediterranean region. Most of the global production comes from Southern Europe, North Africa and the Near East. ${ }^{13}$ The estimated world production in 2002 was 2.6 million tons, in which Spain contributed $40 \%$ to $45 \%$. In 2006, Turkey accounted for about $5 \%$ of world production, similar to the Spanish province of Jaén alone, which is well known for the largest olive groves in the world. Approximately $93 \%$ of European production comes from Spain, Italy and Greece. ${ }^{13}$ Greece devotes $60 \%$ of its cultivated land to olive growing. It is the world's top producer of black olives and has more varieties of olives than any other country. Greece holds third place in olive production when compared to the rest of the world, with more than 132 million trees. Greece produces approximately 350,000 tons of olive oil annually. Approximately $82 \%$ of this production is extravirgin olive oil. About half of the annual Greek olive oil production is exported, but only $5 \%$ of this reflects the origin of the bottled product. Greece exports mainly to European Union (EU) countries, principally Italy, which receives about three quarters of total exports. A large part of US olive oil imports comes from Italy, Spain, and Turkey. ${ }^{13}$ Ever since 25 years ago until now, olive oil production in Al-Jouf, in the Kingdom of Saudi Arabia has been $99.60 \%$ successful for all olive grades. There are more than 13 million olive trees in the area, and more trees are being planted. ${ }^{14}$ Fig. -2 shows the main olive oil-producing countries.

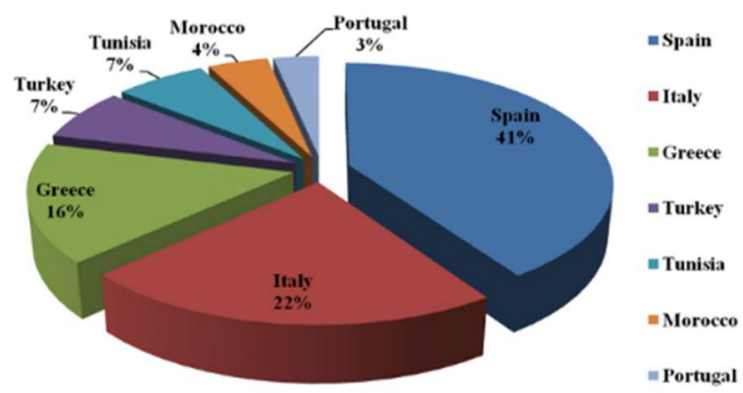

Fig.- 2: The Main Olive Oil producing Countries

\section{Olive Oil}

Olive Oil is a pale yellow to greenish oil obtained from the pulp of olives by separating the liquids from solids. All production begins by transforming the olive fruit into olive paste. This paste is then malaxated to allow the microscopic oil droplets to concentrate. The oil is extracted by means of pressure, which is the traditional method, or centrifugation, which is the modern method. After extraction, the remnant solid substance still contains a small quantity of oil. ${ }^{15}$ Olive oil is usually sold in dark tinted bottles, as this will help to protect the oil from oxidation caused by exposure to intense light. In addition, olive oil is usually 
displayed in a cool area, away from any direct or indirect contact with heat. The cultivars vary considerably in size, shape, oil-content and flavor. The olive oil production industry has great socio-economic importance in Mediterranean countries. ${ }^{16}$ There are many different kinds of olive oil. A few of the different kinds are explained in more detail:

i. Extra virgin olive oil (EVOO) comes from virgin oil production only, contains no more than $0.8 \%$ acidity, and is judged to have a delicious taste. It is used on salads, or added at the table to soups and stews and for dipping.

ii. Virgin olive oil (VOO) comes from virgin oil production only, has an acidity of less than 1.5\%, and is judged to have good taste.

iii. Pure olive oil (POO). Oils labeled as pure olive oil or simply olive oil are usually a mix of both refined and virgin oil production.

iv. Olive oil (OO) is a blend of virgin and refined oil production of no more than $2 \%$ acidity. It commonly lacks a strong flavor.

EVOO is considered to be the best olive oil for its organoleptic characteristics, for its oxidative stability and its chemical composition. It is practically the only vegetable oil that can be consumed directly in its raw state and contains important nutritional elements (vitamins, antioxidants, among others). EVOO contains $98 \%$ to $99 \%$ triacylglycerols (TAGs) and $1 \%$ to $2 \%$ minor components. 17

In the TAGs the main fatty acids are represented by monounsaturates (oleic), with a slight amount of saturates (palmitic, stearic) and an adequate presence of polyunsaturates (linoleic and $\alpha$-linolenic). Some polyunsaturated fatty acids with 18 carbon atoms (linoleic, 18:2 $\omega-6$, and $\alpha$-linolenic, 18:3 $\omega$-3), although indispensable for cell structure and function, cannot be synthesized by the body and must be consumed in food. ${ }^{18}$ The minor components of EVOO are $\alpha$-tocopherol, phenol compounds, carotenoids ( $\beta$-carotene and lutein), squalene, phytosterols, and chlorophyll (in addition to a great number of aromatic substances). Factors that can influence (to a degree) the composition of EVOO, especially in regard to its minor components, are the type of cultivation (cultivar), area of production, time of harvesting, and degree of technology used in its production.

Since ancient times, olive trees have provided food, fuel, timber and medicine for many civilizations. Olive oil has many beneficial uses. It can be used for earwax, ringing ears (tinnitus), lice, wounds, minor burns, psoriasis, stretch marks and for protecting the skin from ultraviolet (UV) damage after sun exposure, among other uses. ${ }^{19}$ In addition, oleic acid present in the oil is also of considerable interest in skincare. It is a strong moisturizer for skin, and a small amount of olive oil may be added to a warm bath for a good and healthy soak for skin. ${ }^{20}$ Olive oil has been used to treat constipation, high cholesterol, high blood pressure, blood vessel problems associated with diabetes, and pain associated ear infections, arthritis, gallbladder disease, and many other health-related problems. Olive oil is also used to treat jaundice, intestinal gas, and meteorism. $^{21}$

\section{Composition of Olive Oil}

The chemical composition of olive oil has been analyzed by many researchers. Abdullah $(2010)^{22}$ studied the chemical composition properties of olive oil, and found that the acid value of FFAs as oleic acid, iodine value, saponification value, and unsaponifiable matter was of $2.4(\mathrm{mg} \mathrm{KOH} / \mathrm{g}), 1.2 \%, 81.4(\mathrm{mg} / 100 \mathrm{~g})$, $189.7(\mathrm{mg} / \mathrm{g})$, and $1.5 \%$ respectively. Al-Gamdi $(2008)^{23}$ reported that olive oil contains $67.8 \%$ oleic acid and $10.79 \%$ linoleic acid. Sodeif (2007) [13] studied the chemical composition of olive oil. The TAGs composition of olive oil are 1,2,3-trioleylglycerol (OOO) 40-59\%, 1-palmitoyl-2,3-dioleoylglycerol (POO) 12-20\%, 1,2-dioleoyl-3-linoleoyl glycerol (OOL) 12.5-20\%, 1-palmitoyl-2-oleoyl-3-linoleoylglycerol (POL) 5.5-7\%, 1-stearoyl-2,3-dioleoylglycerol (SOO) 3-7\%. The fatty acids composition of olive oil are palmitic acid $\left(\mathrm{C}_{16: 0}\right): 7.5-20 \%$, stearic acid $\left(\mathrm{C}_{18: 0}\right): 0.5-5 \%$, oleic acid $\left(\mathrm{C}_{18: 1}\right): 55-83 \%$, linoleic acid $\left(\mathrm{C}_{18: 2}\right)$ : 3.5-21\%, linolenic acid $\left(\mathrm{C}_{18: 3}\right): 3.5-21 \%$. A comparison of fatty acids of olive oil to other seeds oil is shown in Table- $2 .{ }^{24,25}$

The results in the table show compositions of fatty acid for olive oil, black cumin seed oil, palm oil and dabai kernel oil .Palm oil and dabai kernel oil are characterized by the high value of saturated fatty acids due to the high value of palmitic acid, which is $33.8 \%$ and $46.4 \%$ respectively, compared to olive oil and 
black cumin seed oil that have very low values of saturated fatty acids. On the other hand, olive oil is characterized with the higher content of monounsaturated fatty acids due to the high content of oleic acid (64.4\%), while black cumin seed oil, palm oil and dabai kernel oil contain $22.3 \%, 39.7 \%$ and $35.1 \%$ of oleic acid respectively.

Table-2: Fatty Acid Compositions (\%) of Some Selected Seed Oils.

\begin{tabular}{c|c|c|c|c}
\hline \multirow{2}{*}{ Fatty Acids } & \multicolumn{4}{|c}{ Composition (\%) } \\
\cline { 2 - 5 } & Olive Oil & Black Cumin Seed Oil & Palm Oil & Dabai Kernel Oil \\
\hline Myristic $\mathrm{C}_{14: 0}$ & 12.9 & $\mathrm{n} / \mathrm{a}$ & 9.2 & 9.3 \\
\hline Palmitic $\mathrm{C}_{16: 0}$ & 9.9 & 12.1 & 33.8 & 46.4 \\
\hline Stearic $\mathrm{C}_{18: 0}$ & 2.3 & 3.0 & 3.7 & 4.9 \\
\hline Arachidic $\mathrm{C}_{20: 0}$ & 0.4 & 0.2 & 0.3 & 0.2 \\
\hline Saturated & 25.5 & 15.3 & 47.9 & 60.8 \\
\hline Palmitoleic $\mathrm{C}_{16: 1}$ & 0.7 & 0.2 & 0.2 & 0.5 \\
\hline Oleic $\mathrm{C}_{18: 1}$ & 64.4 & 22.3 & 39.6 & 35.1 \\
\hline Gadoleic $\mathrm{C}_{20: 1}$ & 0.3 & 0.4 & 0.2 & $\mathrm{n} / \mathrm{a}$ \\
\hline Lignoceric $\mathrm{C}_{24: 0}$ & 0.4 & 0.3 & 0.1 & $\mathrm{n} / \mathrm{a}$ \\
\hline Monounsaturated & 65.8 & 23.2 & 40.1 & 35.3 \\
\hline Linolenic $\mathrm{C}_{18: 3}$ & 0.6 & 0.3 & 0.3 & 0.2 \\
\hline Linoleic $\mathrm{C}_{18: 2}$ & 1.9 & 58.5 & 0.7 & 0.7 \\
\hline Linoleic $\mathrm{C}_{18: 2} \mathrm{n} 6$ & 5.1 & $\mathrm{n} / \mathrm{a}$ & 10.9 & 2.8 \\
\hline Eicosapentaenoic $\mathrm{C}_{20: 5}$ & 0.4 & $\mathrm{n} / \mathrm{a}$ & $\mathrm{n} / / \mathrm{a}$ & $\mathrm{n} / \mathrm{a}$ \\
\hline Polyunsaturated & 7.9 & 58.8 & 11.9 & 3.8 \\
\hline
\end{tabular}

As saturated fats increase the risk of cardiovascular diseases and diabetes, palm oil and dabai kernel oil, which are rich in palmitic acid have negative effects on human health. At the same time, olive oil is rich in oleic acid, which is the main component of monounsaturated fats of olive oil. Oleic acid plays an important role in body health. Most experts agree that oleic acid is one of the better fats for humans to consume. Oleic acid helps regulate bodily functions and helps the body absorb nutrients, especially the fat-soluble vitamins $\mathrm{A}, \mathrm{D}, \mathrm{E}$ and $\mathrm{K}$. It can lower total cholesterol levels by raising blood concentrations of high-density lipoproteins while reducing low-density lipoproteins, also known as the "bad" cholesterol. It has been shown to slow the development of heart disease and also promotes the production of antioxidants, elements that can help trap harmful free radicals in the body. Monounsaturated fats provide energy and help to keep the hair and skin healthy. Therefore, olive oil is a good source in many applications such as biological, cosmetics and nutrition-related applications. ${ }^{18,19}$

\section{Black Cumin Products and their Characteristics}

Black cumin seed is an annual herbaceous plant belonging to the Ranunculaceae family growing in countries bordering the Mediterranean Sea. ${ }^{26}$ The scientific classification of black cumin is shown in Table3.

Table-3: The Scientific Classification of Black Cumin Seed

\begin{tabular}{c|c}
\hline Scientific & Classification \\
\hline Kingdom & Plantae \\
\hline Order & Ranunculales \\
\hline Family & Ranunculaceae \\
\hline Genus & Nigella \\
\hline Species & N. sativa \\
\hline
\end{tabular}

Black cumin seed is an annual herbaceous plant cultivated in different parts of the world, mainly in countries bordering the Mediterranean Sea. It grows up to 20 to 30 centimeters tall, with finely divided, linear leaves. The flowers are delicate and usually colored pale blue and white, usually with 5 to 10 petals. The fruit is a large and inflated capsule composed of 3 to 7 united follicles, each containing numerous seeds. The seed is used as a spice. Figure-3(a) and (b) show the flower and seeds of black cumin, respectively. Black cumin 
seed is the English name. It is also known by its Latin name - Nigella sativa, and Arabic name Habbat Albaraka (Habba Souda). The seeds are used extensively for flavoring and medicinal purposes. It can be used in the preparation of a traditional sweet dish and eaten with honey and syrup and for sprinkling on bread, flavoring of foods, especially bakery products and cheese. ${ }^{27}$ The seeds are also used in traditional medicine as a natural remedy for several illnesses that include asthma, hypertension, diabetes, inflammation, cough, bronchitis, headache, fever, dizziness and influenza, and as a carminative, diuretic, lactagogue and vermifuge. ${ }^{28}$

(a)

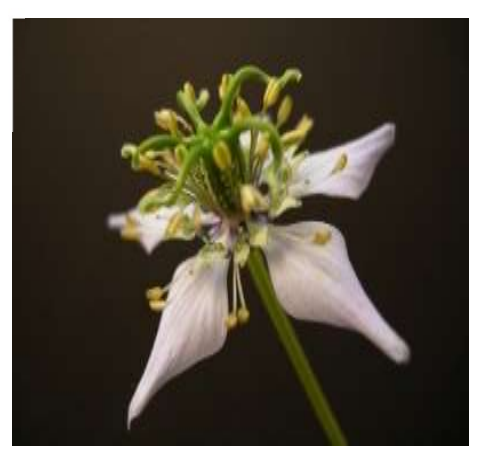

(b)

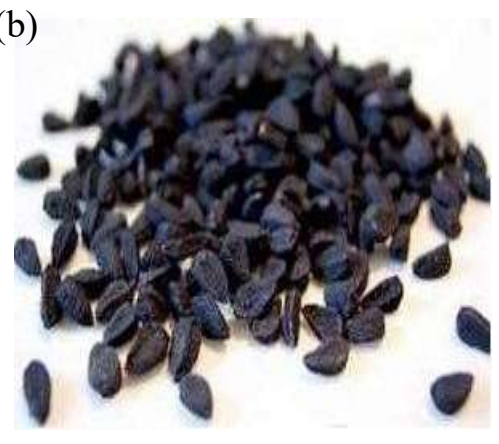

Fig.-3: (a) The Flower of Black Cumin and (b) The Black Cumin Seeds

\section{Composition of Black Cumin Seed Oil(BCSO)}

Black cumin seed oil is light amber in color with a characteristic herbaceous aroma. Today, BCSO is known for its nutritive properties and is used throughout the nutritional supplement and personal care industries for various applications. Black cumin (Nigella sativa) does, in fact have remarkable healing and health properties that make it one of the most powerful medicinal plants known to man. This remarkable oil contains over 100 chemical compounds that have been analyzed by many researchers.

Muhammad et al. (2009) ${ }^{29}$ studied the nutritional profile of indigenous cultivar of black cumin seeds from Pakistan and antioxidant potential of its fixed and essential oil, and whether it contains appreciable quantities of carbohydrates, proteins and fats. Moreover, potassium, calcium, phosphorous and magnesium were predominant minerals, whilst considerable quantities of sodium, iron, manganese, zinc and copper were also present. Characterization of fixed oil enumerated that polyunsaturated fatty acids were the dominating fraction i.e., $60.2 \pm 1.5 \%$, as compared to saturated and monounsaturated fatty acids i.e., $16.7 \pm 0.9$ and $22.5 \pm 0.6 \%$ respectively. Carotenoids and tocopherols were $450.7 \pm 16.2 \mathrm{mg} / \mathrm{kg}$-oil, whereas thymoquinone contents were observed to be $201.3 \pm 13.2 \mathrm{mg} / \mathrm{kg}$ of seeds. In comparison, analysis of essential oil revealed that it contains functional ingredients like thymoquinone, dihydrothymoquinone, $\mathrm{p}$ cymene, carvacrol, $\alpha$-thujene, thymol, $\alpha$-pinene, $\beta$-pinene and t-anethole as major constituents.

Eray Tulukcu (2010) $)^{30}$ determined the fatty acid composition of the black cumin (Nigella sativa) samples obtained from a total of ten different regions in Turkey, Iran and Syria and the comparison of variations in species. The fatty acid compositions of black cumin samples were determined by gas chromatography (GC). According to the results, the fatty acid composition of the black cumin significantly varies based on which type of species it belongs to. These results indicated that black cumin oil is a functional food because of the high unsaturated fatty acid values and could be used as natural agent in animal and human nutrition.

Kaskoos $(2011)^{31}$ described the fatty acid composition of black cumin oil from Iraq. The major fatty acids of the oil were linoleic acid (42.8\%), oleic acid (16.6\%), palmitic acid (8.5\%), eicosatrienoic acid (4.7\%), eicosapentaenoic acid (EPA) (6\%) and docosahexaenoic acid (DHA) (3\%). High unsaturated fatty acid content signified it to offer considerable resistance to oxidative rancidity during storage and health benefits on use. A comparison of fatty acids of black cumin seed to other seeds oil is shown in Table 3 . As can be seen from Table 3, due to the high value of linoleic acid (58.5\%), BCSO is characterized by the high content of polyunsaturated fatty acids compared to olive oil, palm oil and dabai kernel oil. Linoleic acid plays an important role in the human body. It is a polyunsaturated fatty acid used in the biosynthesis of arachidonic acid and thus some prostaglandins. It is found in the lipids of cell membranes. Linoleic acid has many 
functions in the human body, such as providing antioxidant defense, improving blood cells, normalizing the level of glucose, and the reduction of body fat. Linoleic acid is an essential fatty acid that must be consumed for proper health. Therefore, BCSO is good source to use in medical applications. ${ }^{9}$

\section{Biological Activities}

Essential oils in olive and black cumin have many biological activities that help to improve the immune system, such as:

\section{Antioxidant Activity}

Antioxidant activity of cellular metabolism occurs in human bodies in order to create energy and maintain life. These reactions cause the chemical bonds in our bodies to split apart. When a chemical bond in our bodies is splitting in a manner that causes one of the molecules to have an unpaired electron, a free radical is created. The danger lies in their reaction with portions of the cell, such as the membrane or DNA. Since these free radicals are not stable, they will react with other compounds very rapidly in order to become stable again by capturing their electron. Examples of free radicals are hydroxyl radical ( $\mathrm{HO} \bullet$ ), carbene molecule $\left(: \mathrm{CH}_{2}\right)$, and superoxide anion $\left(\bullet \mathrm{O}_{2}\right)$. This causes severe damage and disruption in a cell. However, there are ways in which we can fight the destruction of free radicals. Diets rich in fruits and vegetables introduce antioxidants into our bodies, which counteract free radicals or volatile compounds and supplements are able to enter our body and penetrate all of our cells within minutes. Squalene, thymoquinon, carvacol and vitamin E act as antioxidants, which are supplements that help our bodies in the process of repair and renewal. Antioxidants are nutrients and enzymes that reduce oxidative stress. An antioxidant puts a stop to the cycle of free radical cell damage by donating one of its electrons to the unstable free radical. Because the antioxidant is stable in either form, donating an electron does not cause it to become a free radical. In fact, their job is to prevent cell damage. ${ }^{32}$

\section{Anti-inflammatory Activity}

Anti-inflammatory activity refers to the property of a substance or treatment that reduces inflammation. Anti-inflammatory drugs make up about half of analgesics. The anti-inflammatory activities of BCS volatile compounds and their major constituents were evaluated by measuring their capacity to inhibit cellular nitric oxide (NO) generation. Nitric oxide is an endogenous free radical type of species that is synthesized from L-arginine by nitric oxide synthase (NOS) in various tissues. This radical is an important regulator of physical homeostasis, whereas large amounts have been closely correlated with the pathophysiology of a variety of diseases and inflammations. ${ }^{33}$ Therefore, the inhibition of NO production may be a useful strategy for the treatment of various inflammatory disorders. Literature data indicates that $\alpha$-thujene, $\beta$-pinene, $p$ cymene, $\gamma$-terpinene, terpinolene, 4-terpineol, thymoqiunone, carvacrol, longifolene and peonol mediate their inhibitory effect on NO production through the reduction of inducible NOS mRNA and protein expressions. ${ }^{34}$

\section{Anti-microbial Activity}

The findings discussed above indicate that $\beta$-pinene, $p$-cymene, $\gamma$-terpinen, terpinolene, 4 -terpineol, thymoqiunone, carvacrol and 3,5-dimethyl cyclohexanol compounds of BCSO possess potential immunomodulatory effects. Therefore, these compounds of BCSO have been reported to exert antimicrobial activities, including anti-bacterial, anti-fungal and anti-viral effects. ${ }^{9}$

\section{Antibacterial Activity}

The volatile compounds of BCSO, such as $\beta$-pinene, $p$-cymene, $\gamma$-terpinen, terpinolene, 4-terpineol, thymoqiunone, carvacrol and 3,5-dimethyl cyclohexanol have antibacterial activity due to several sites of action at the cellular level. One of the possibilities for action is the generation of irreversible damage to the membrane of bacterial cells, that induce material losses (cytoplasmic), leakage of ions, loss of energy substrate (glucose, ATP), leading directly to the lysis of bacteria (cytolysis) and eventually to its death. Another possibility of action is inhibition of production of amylase and protease, which stop the toxin production, electron flow and result in coagulation of the cell content. ${ }^{35-37}$ 


\section{Antifungal Activity}

The volatile compounds of BCSO such as thymoqiunone carvacrol and 3,5-dimethyl cyclohexanol act as antifungal activity is quite similar to those described for fungal. However, two additional phenomena inhibiting the action of yeast are worth mentioning: the establishment of a $\mathrm{pH}$ gradient across the cytoplasmic membrane and the blocking of energy production of yeasts which involve the disruption of the fungal membrane. ${ }^{38}$

\section{Antiviral Activity}

Antiviral compounds found in many different volatile compounds such as $\beta$-pinene, $p$-cymene, $\gamma$-terpinen and terpinolene extract of BCSO. The antiviral activity of the volatile compounds is principally due to direct virucidal effects (by denaturing viral structural proteins or glycoproteins). Proposed mechanisms suggest that volatile compounds interfere with the virus envelope by inhibiting specific processes in the viral replication cycle or by masking viral components, which are necessary for adsorption or entry into host cells. Thus, they prevent cell-to-cell virus diffusion. ${ }^{38,39}$ As can be seen from the table review, EVOO and BCSO have biological properties. They can cause good medicinal effects of this mixture. Table-4 shows all biological activities of olive and black cumin essential oils.

Table-4: Biological Activities of Some Olive and Black Cumin Seed Oil Compounds

\begin{tabular}{c|c|c}
\hline Compounds & Biological Activities & Reference \\
\hline Squalene & Antioxidant & 40 \\
\hline$\alpha$-Thujene & Anti-inflammatory & 41 \\
\hline$\beta$-Pinene & Antiviral, Antibacterial, Anti-inflammatory & 38,41 \\
\hline$p$-Cymene & Antiviral, Antibacterial, Anti-inflammatory & 38,41 \\
\hline$\gamma$-Terpinene & Antibacterial, Antiviral, Anti-inflammatory, Antifungal, Antioxidant & 42 \\
\hline Terpinolene & Antibacterial, Antiviral, Anti-inflammatory & 34 \\
\hline 4-Terpineol & Antibacterial, Anti-inflammatory & 34 \\
\hline Thymoqiunone & Antioxidant, Anti-inflammatory, Antifungal, Antibacterial. & $32,34,38$ \\
\hline Carvacrol & Antibacterial, Antifungal, Anti-inflammatory, Antioxidant & 38,43 \\
\hline (3,5-Dimethyl) & Antibacterial, Antifungal. & 44 \\
\hline cyclohexanol & Anti-inflammatory & 34 \\
\hline Longifolene & Anti-inflammatory & 45 \\
\hline Peonol & Antioxidant, Anti-inflammatory & 46,47 \\
\hline Vitamin E & &
\end{tabular}

\section{CONCLUSION}

Oleic acid is a monosaturated fatty acid (omega 9) found in olive oil. Linoleic acid is a polyunsaturated fatty acid (omega 6) found in black cumin seed oil. Omega 9 and 6 are unsaturated fatty acid and substances that the body needs in order to maintain cellular health as well as to prevent any inflammation on the skin. Unsaturated fatty acid deficiency causes dermatitis, such as eczema. TAGs from both are very helpful to the skin. TAGs contribute to healthy, moisture-filled and lustrous skin. The presence of unsaturated fatty acids and TAGs in the EVOO-BCSO mixture helps to reduce symptoms and treat many types of disease.

\section{ACKNOWLEDGEMENT}

We would like to thank Universiti Kebangsaan Malaysia for the grand numbers (UKM-AP2011-17, UKMGUP-NBT-2016-058) and the Ministry of Science, Technology and Innovation for funding the project (MOSTI 05-01-02-SF0199).

\section{REFERENCES}

1. D. R. Bickers, H. W. Lim, D. Margolis, M. A. Weinstock, C. Goodman, E. Faulkner, C. Gould, E. Gemmen and T. Dall, Journal of the American Academy of Dermatology, 55(3), 490(2006), https://doi.org/10.1016/j.jaad.2006.05.048

2. M. I. Asher, S. Montefort, B. Björkstén, C. K. Lai, D. P. Strachan, S. K. Weiland and H. Williams, Lancet, 26, 733(2006), https://doi.org/10.1016/S0140-6736(06)69283-0 
RASĀYAN J. Chem.

Vol. 14 | No. 4 |2469-2477| October- December | 2021

3. P. Reid, M. S. Lewis-Jones, Clinical and Experimental Dermatology, 20, 38(1995), https://doi.org/10.1111/j.1365-2230.1995.tb01280.x

4. S. G. O Johansson, T. Bieber, R. Dahl, P. S. Friedmann, B. Q. Lanier, R. F. Lockey, C. Motala, J. A. O. Martell, T. A. E Platts-Mills, J. Ring. Journal of Allergy and Clinical Immunology, 113(5), 832(2004), https://doi.org/10.1016/j.jaci.2003.12.591

5. N. Salih and J. Salimon, Biointerface Research in Applied Chemistry, 11(5), 13303(2021), https://doi.org/10.33263/briac115.1330313327

6. C. Chong, British Journal of Pharmacology, 139(6), 1146(2003), https://doi.org/org/10.1038/sj.bjp.0705360

7. N. Al-Arafi, N. Salih and J. Salimon, RASĀYAN Journal of Chemistry, 14(3), 1809(2021), https://doi.org/10.31788/RJC.2021.1436222

8. E. Market and F. N. Papavasiliou, PLoS Biology, 1(1), e16(2003), https://doi.org/10.1371/journal.pbio.0000016

9. L. S. Mohamed, International Immunopharmacology, 5, 1749(2005), https://doi.org/10.1016/j.intimp.2005.06.008

10. N. Al-Arafi, N. Salih and J. Salimon, Indonesian Journal of Chemistry, 21(3), 659(2021), https://doi.org/10.22146/ijc.59694

11. N. Salih and J. Salimon, Biointerface Research in Applied Chemistry, 12(1), 1185(2022), https://doi.org/10.33263/briac121.11851207

12. J. C. Su, A. S. Kemp, G. A. Varigos and T. M. Nolan, Archives of Disease in Childhood, 76(2), 159(1997), https://doi.org/10.1136/adc.76.2.159

13. A. Sodif, Olive Oil Phytosterols, Tracing of Adulteration with Hazelnut Oil and Chemical Interesterification, Doctoral Thesis, Swedish University of Agricultural Sciences (2007).

14. N. Farhan, N. Salih and J. Salimon, Oilseeds and Fats, Crops and Lipids, 28, 11 (2021), https://doi.org/10.1051/oc1/2020075

15. J. L. Mueller, J. L. Page and M. F. Wolfner, Genetics, 175(2), 777(2007), https://doi.org/10.1534/genetics.106.065318

16. J. A. Alburquerque, J. Gonzalvez, D. Garcia, J. Cegarra, Bioresourse Technology, 98, 940 (2007), https://doi.org/10.1016/j.biortech.2006.04.014

17. A. Bendini, L. Cerretani, A. Carrasco-Pancorbo, A. M. Gómez-Caravaca, A. Segura-Carretero, A. Fernández-Gutiérrez and G. Lercker, Molecules, 12(8), 1679(2007), https://doi.org/10.3390/12081679

18. V. Publio, V. Marzia, Clinics in Dermatology, 27(2), 159(2009), https://doi.org/10.1016/j.clindermatol.2008.01.008

19. B. Leslie and W. Edmund, Olive Oil in Botanical Cosmeceuticals. Olives and Olive Oil in Health and Disease Prevention, 1117 (2010), https://doi.org/10.1016/b978-0-12-374420-3.00122-4

20. N. S. Al-Waili, Complementary Therapies in Medicine, 11, 226(2003), https://doi.org/10.1016/s09652299(03)00120-1

21. H. T. Khor, R. Raajeswari and G. Muralidharan, Malaysian Journal of Nutrition, 4, 73(1998).

22. A. Abdullah, Olive Oil: Official Standards in Relation to Its Biological Active Constituents, King Abdul-Aziz University (2010).

23. D.O. Edem, Plant Food for Human Nutrition, 57, 319(2002), https://doi.org/10.1023/a:1021828132707

24. A. Azrina, K. P. Nagendra, E. K. Hock, A. Nurnadia, M. Alina, I. Amin and A. Zulkhairi, Journal of Food Composition and Analysis, 23 and 772(2010), https://doi.org/10.1016/j.jfca.2010.03.026

25. B. Matthaus, M.M. Özcan, Czech Journal of Food Sciences, 29, 145(2011), https://doi.org/10.17221/206/2008-cjfs

26. M. B. Atta, Food Chemistry, 83(1), 63(2003), https://doi.org/10.1016/s0308-8146(03)00038-4

27. H. R. H. Takruri, M. A. F. Dameh, Journal of the Science of Food and Agriculture, 76(3), 404(1998), https://doi.org/10.1002/(sici)1097-0010(199803)76:3\%3C404::aid-jsfa964\%3E3.0.co;2-1

28. H. Hossein, B. S. Fazly and M. H. Maryam, Pharmacolgyonline, 2, 429(2007).

29. T. S. Muhammad, S. B. Masood, M. A. Faqir, J. Amer, A. Saeed and N. Muhammad, Pakistan Journal of Botany, 41(3), 1321(2009). 
RASĀYAN J. Chem.

Vol. 14 | No. 4 |2469-2477| October- December | 2021

30. E. Tulukcu, African Journal of Agricultural Research,6, 892(2010), https://doi.org/10.5897/AJAR10.286

31. R. A. Kaskoos, Research Journal of Medicinal Plant, 5, 85(2011), https://doi.org/10.3923/rjmp.2011.85.89

32. M. Chern, W. Bai, X. Chen, E. Patrick and C. Pamela, Peer Journal, 1, e28(2013), https://doi.org/10.7717/peerj.28

33. M. A. Marletta, Journal of Biological Chemistry, 15, 12231(1993).

34. A. El-Mahmoudy, H. Matsuyama, M. A. Borgan, Y. Shimizu, M. G. El-Sayed, N. Minamoto and T. Takewaki, International Immunopharmacology, 2(11), 1603(2002), https://doi.org/10.1016/s15675769(02)00139-x

35. F. Bakkali, S. Averbeck, D. Averbeck and M. Idaomar, Food and Chemical Toxicology, 46(2), 446(2008), https://doi.org/10.1016/j.fct.2007.09.106

36. K. A. Hammer, C. F. Carson, J. A. Dunstan, J. Hale, H. Lehmann, C. J. Robinson, S. L. Prescott and T. V. Riley, Microbiology and Immunology, 52(11), 522(2008), https://doi.org/10.1111/j.13480421.2008.00070.x

37. R. D. Pasqua, G. Betts, N. Hoskins, M. Edwards, D. Ercolini and G. Mauriello, Journal of Agricultural and Food Chemistry, 55(12), 4863(2007), https://doi.org/10.1021/jf0636465

38. S. Bourgou, A. Pichette, B. Marzouk and J. Legault, South African Journal of Botany, 76(2), 210(2010), https://doi.org/10.1016/j.sajb.2009.10.009

39. M. A. Saddi, F. Sanna, L. Cottiglia, L. Chisu, L. Casu, A. Bonsignore and A. De Logu, Annals of Clinical Microbiology and Antimicrobials, 6, 10(2007), https://doi.org/10.1186/1476-0711-6-10

40. B. Das, The science behind squalene - The human antioxidant, $2^{\text {nd }}$ ed., Canada: Toronto Medical Publishing (2005).

41. K.H.C. Baser and G. Buchbauer, Handbook of Essential Oils: Science, Technology, and Applications, CRC Press NW (2010).

42. H. Schulz and M. Baranska, Vibrational Spectroscopy, 43(1), 13(2007), https://doi.org/10.1016/j.vibspec.2006.06.001

43. D. P. DeSousa, G .A. S. Júnior, L. N. Andrade and J. S. Batista, Records of Natural Products, 52, 117(2011).

44. V. Mahyavanshi, S. I. Marjadi and R. Yadav, Arabian Journal of Chemistry, 10, 804(2017), https://doi.org/10.1016/j.arabjc.2012.12.009

45. C. Chong, British Journal of Pharmacology, 139(6), 1146(2003), https://doi.org/10.1038/sj.bjp.0705360

46. C. Schneider, Molecular Nutrition and Food Research, 49(1), 7(2005), https://doi.org/10.1002/mnfr.200400049

47. B. C. Herrera, Journal of Physiology and Biochemistry, 57, 43(2001), https://doi.org/10.1007/bf03179812

[RJC-6525/2021] 